Revista Bioética

\title{
ATUALIZAÇÃO
}

\section{Cuidados paliativos e autonomia de idosos expostos à covid-19}

Ana Sarah Vilela de Oliveira ${ }^{1}$, Juliana Campos Machado ${ }^{2}$, Luciana Dadalto $^{3}$

1. Universidade Federal de Lavras, Lavras/MG, Brasil. 2. Centro Universitário de Belo Horizonte, Belo Horizonte/MG, Brasil. 3. Centro Universitário Newton Paiva, Belo Horizonte/MG, Brasil.

\section{Resumo}

Este artigo visa contextualizar o cenário da pandemia da covid-19 em relação aos idosos, tendo em vista a imposição de critérios etários em protocolos para alocação de recursos escassos, evidenciando um tipo de discriminação à pessoa idosa que desconsidera sua biografia e valores. Objetivou-se defender a autonomia na velhice, bem como ressaltar a necessidade de acesso aos cuidados paliativos, independentemente de haver ou não recursos. Para tanto, adotou-se como método a investigação bibliográfica e jurídico-dogmática, com enfoque qualitativo. Conclui-se que em cenário em que o interesse coletivo deve preponderar, os cuidados paliativos são cruciais para respeitar a autonomia e a dignidade do idoso, garantindo melhores experiências no fim de vida.

Palavras-chave: Idoso. Cuidados paliativos. Bioética. Autonomia pessoal.

\section{Resumen}

\section{Cuidados paliativos y la autonomía de las personas mayores expuestas a la covid-19}

Este artículo busca contextualizar el escenario de la pandemia de la covid-19 respecto a las personas mayores, teniendo en vista la imposición de criterios de edad en protocolos para determinar la asignación de recursos escasos, lo que pone de manifiesto un tipo de discriminación hacia las personas mayores que desprecia su biografía y valores. El objetivo es defender la autonomía en la vejez, así como resaltar la necesidad de acceso a los cuidados paliativos, independientemente de si hay recursos o no. Para ello se adoptó como método la investigación bibliográfica y legal-dogmática, con un enfoque cualitativo. Se concluye que, en un escenario en que el interés colectivo debe ser preponderante, los cuidados paliativos son cruciales para respetar la autonomía y la dignidad de las personas mayores, y garantizarles mejores experiencias al final de la vida.

Palabras clave: Anciano. Cuidados paliativos. Bioética. Autonomía personal.

\section{Abstract}

Palliative care and autonomy of older adults exposed to Covid-19

This article aims to contextualize the Covid-19 pandemic regarding older adults in view of age-related criteria to allocate scarce healthcare resources imposed in some prevention protocols, evidencing discrimination against elderly people for disregarding their biography and values. The goal of this study is to defend autonomy in old age and highlight the need for access to palliative care, regardless of whether resources are available. To this end, it conducts a bibliographic and legal-dogmatic investigation with a qualitative approach. The research concludes that in a situation where collective interest should prevail, palliative care is crucial to respect the autonomy and dignity of the aged, granting them a better experience at the end of life.

Keywords: Aged. Palliative care. Bioethics. Personal autonomy.

Declaram não haver conflito de interesse. 
O primeiro caso de covid-19, causada pelo Sars-CoV-2, foi registrado em Wuhan, na província de Hubei, China, e logo a doença se espalhou por todo o mundo. A Organização Mundial da Saúde (OMS) caracterizou a situação como pandemia no dia 11 de março de $2020^{1}$. A velocidade de propagação do vírus, a dificuldade de contê-lo e as manifestações clínicas graves foram surpreendentes, haja vista que se conhecem outros seis coronavírus humanos, que representam a segunda maior causa de resfriado comum no mundo e nas últimas décadas raramente causaram doenças mais graves ${ }^{1}$.

A exemplo de outros coronavírus, o Sars-CoV-2 causa doença respiratória potencialmente grave em alguns indivíduos ${ }^{2}$. Dada a alta capacidade de transmissão e a falta de vacina e medicamento específicos, as iniciativas governamentais têm se baseado em práticas de prevenção, como distanciamento social, uso de máscaras e medidas de higienização (lavar bem as mãos, evitar tocar olhos, nariz e boca até que as mãos sejam higienizadas, entre outras). Assim, cabe tanto ao Estado quanto à população atuar de modo integral para atenuar o contágio enquanto medidas mais eficazes, como vacinas, não são desenvolvidas.

Diante desse cenário, equipes de saúde e órgãos governamentais se veem na difícil posição de enfrentar o vírus contando com poucas evidências científicas. O que já se sabe é que o Sars-CoV-2 causa infecções respiratórias e intestinais que podem levar a complicações, como síndrome respiratória aguda grave, lesão cardíaca e infecção secundária ${ }^{3}$. Todas essas complicações levam a alta taxa de hospitalização, com potencial para saturar e colapsar sistemas de saúde.

O maior grupo de risco é formado por idosos e pacientes com doenças crônicas ${ }^{1}$, pois o sistema imunológico deficiente dessa população aumenta a incidência de doenças infectocontagiosas ${ }^{2}$. Nesse contexto, idosos se tornam duplamente vulneráveis, pois as alterações do organismo que reduzem a capacidade do sistema imunológico, naturais ao processo de envelhecimento, se somam à gravidade dos sintomas da covid-19, debilitando ainda mais sua fisiologia.

No entanto, a escassez de recursos gerada pela demanda extraordinária por atendimento, insumos, tecnologias e recursos humanos tem desafiado instituições, que se viram obrigadas a escolher como distribuir riscos e benefícios entre pacientes. Por vezes, tem-se adotado o critério etário, como no caso do Colégio Italiano de Anestesia, Analgesia, Ressuscitação e Cuidado Intensivo (Siaarti) ${ }^{4}$ e da
Associação de Medicina Intensiva Brasileira (Amib) ${ }^{5}$, que reviu sua primeira recomendação após cuidadosa análise, considerando discriminatória a forma como tal critério vinha sendo usado ${ }^{6}$. Desse modo, em alguns países, entre eles a Itália ${ }^{7}$, a população idosa vem sofrendo discriminação etária ao ser preterida no recebimento de cuidados, em tipo de segregação social que desconsidera a história do sujeito e o respeito a sua dignidade.

É importante compreender a velhice como processo natural e inevitável, o que, no caso brasileiro, é imprescindível para tornar efetivas as diretrizes tanto da Constituição Federal de $1988^{\circ}$ quanto do Estatuto do Idoso ${ }^{9}$. Porém, para que isso ocorra, o ambiente deve ser propício ao envelhecimento saudável e devidamente pautado no respeito à vida e aos valores da pessoa idosa, garantindo o exercício da autonomia para que as experiências no final da vida sejam as melhores possíveis.

Diante das incertezas que surgem no cenário da covid-19, é premente avaliar as melhores condutas para respeitar a pessoa idosa, considerando os princípios bioéticos de beneficência, não maleficência, justiça e autonomia. Nesse contexto, a OMS ${ }^{10}$ tem papel crucial, pois, além de já ter definido o conceito de cuidados paliativos - que será abordado no decorrer do estudo -, a entidade elaborou o manual Integrating palliative care and symptom relief into the response to humanitarian emergencies and crises $^{11}$.

A obra faz parte de uma série de publicações da OMS sobre assistência paliativa e visa orientar sua integração ao alívio de sintomas nos sistemas de saúde. Ainda que não sejam a resposta para a escassez de recursos, esses cuidados estão de acordo com os preceitos bioéticos e são imprescindíveis no atual cenário. Quando a tecnologia médica não é mais capaz de assegurar, por si só, o prolongamento da vida, a assistência paliativa pode aliviar o sofrimento e cuidar do paciente nas dimensões física, psicológica, social, moral e espiritual.

\section{Escolha de Sofia em tempos de covid-19}

De acordo com Leitão Júnior e Mousinho ${ }^{12}$, a expressão "escolha de Sofia" (Sophie's choice) provém do filme estadunidense de mesmo nome lançado em 1982, baseado no romance de William Styron. O drama conta a história de Sofia, polonesa e filha de pai antissemita, presa em Auschwitz durante a Segunda Guerra sob acusação de contrabando. A escolha a que o título alude tem como 
cenário o campo de concentração, onde a personagem se vê obrigada a salvar da execução apenas uma de suas duas crianças, caso contrário ambas morreriam. A expressão, portanto, refere-se à tomada de decisão em condições de enorme pressão e sacrifício, e pode ser traduzida no âmbito jurídico e bioético como "escolhas difíceis" ou, na prática, como "escolhas trágicas" 12 .

O impasse que aqui se pretende discutir é o da escolha de quem receberá os escassos recursos. Por exemplo, em situação hipotética na qual há dois pacientes com covid-19 - um idoso de 80 anos que respeitou o período de quarentena e um jovem de 25 anos que não a respeitou - e apenas um leito de unidade de terapia intensiva (UTI), quem deve receber o recurso ${ }^{13}$ ? Pensando racionalmente, a resposta é quase instintiva: aquele que tem mais chances de viver. No entanto, a questão é complexa e já tem sido enfrentada na prática em vários lugares do mundo.

É fato que em situações de catástrofe alguns pacientes podem não ter todas as necessidades atendidas, mas estes jamais poderão ficar sem cuidados - ainda que a assistência seja apenas paliativa, visando atenuar sua dor. Por outro lado, é inerente à situação da pandemia considerar a gravidade do quadro clínico e a possibilidade de sobrevivência como critérios de alocação de recursos. Assim, é fundamental elaborar protocolos com escores claros e objetivos que justifiquem o não atendimento à necessidade constatada e demandada pelo paciente.

Nesse sentido, a Sociedade Brasileira de Bioética (SBB) publicou a Recomendação $1 / 2020^{14}$, que aborda fundamentos e aspectos éticos para enfrentar a pandemia de covid-19 no Brasil, tratando da alocação de recursos e do uso igualitário das tecnologias em saúde. O documento defende a proteção dos mais vulneráveis e destaca o papel imprescindível do Sistema Único de Saúde (SUS). Defende-se também o direito de todos ao melhor tratamento e acesso igualitário aos leitos de UTI, sejam públicos ou privados, recomendando-se, inclusive, que se apliquem os princípios da Declaração Universal sobre Bioética e Direitos Humanos (DUBDH) ${ }^{15}$ para definir parâmetros em caso de insuficiência de leitos.

A recomendação da $\mathrm{SBB}^{14}$ se fundamenta no artigo 50 da Constituição brasileira ${ }^{8}$ e no Pacto Internacional dos Direitos Econômicos, Sociais e Culturais, adotado pela Organização das Nações Unidas em 1966, que prevê no parágrafo $1^{\circ}$ de seu artigo 12 o respeito ao direito de toda pessoa de desfrutar o mais elevado nível de saúde física e mental ${ }^{16}$.
Consideram-se ainda os direitos preconizados no artigo 60 da Constituição e o disposto no artigo 25 da Declaração Universal dos Direitos Humanos: todo ser humano tem direito a um padrão de vida capaz de assegurar a si e a sua família saúde e bem-estar, inclusive alimentação, vestuário, habitação, cuidados médicos e os serviços sociais indispensáveis, e direito à segurança em caso de desemprego, doença, invalidez, viuvez, velhice ou outros casos de perda dos meios de subsistência fora de seu controle $^{17}$.

Na Itália, o Siaarti afirmou que, caso não se adotasse o critério etário, a alocação de recursos seguiria o processo mais comumente utilizado em atendimentos de UTI em todo o mundo: internar quem chega primeiro, e não tratar pacientes que chegam quando já não há mais leitos ${ }^{4}$. Ademais, os especialistas do referido órgão destacaram que, quando há grande fluxo de pacientes e uma pessoa internada não responde ao tratamento, a decisão de colocá-la sob cuidados paliativos não deverá ser adiada ${ }^{4}$.

O grupo de trabalho de bioética da Sociedade Espanhola de Medicina Intensiva, Crítica e de Unidades Coronarianas (Semicyuc), com aval da Sociedade Espanhola de Medicina Interna, publicou recomendações éticas para tomar decisões em UTI em meio à situação excepcional da pandemia ${ }^{18}$. As diretrizes priorizam aqueles que mais se beneficiarão do cuidado, estabelecendo escores específicos de prioridade (que vão de 1 a 4). A instituição argumenta que esse tipo de planejamento é imprescindível para garantir a aplicação adequada dos recursos e o respeito à vida, ressalvando, porém, que critérios de triagem só se justificam depois que todos os esforços para aumentar a disponibilidade de recursos forem esgotados. A Semicyuc destaca justiça, dever de cuidar e de administrar recursos, transparência, consistência, proporcionalidade e responsabilidade como princípios-chave na gestão da crise.

No Brasil, a Amib, em conjunto com a Associação Brasileira de Medicina de Emergência, publicou recomendações sobre alocação de recursos escassos durante a pandemia ${ }^{5}$. 0 documento se baseia em protocolo de triagem proposto por Biddison e colaboradores ${ }^{19}$ e é semelhante ao modelo de White e colaboradores ${ }^{20,21}$, apresentando três objetivos: salvar o maior número de pessoas; salvar o maior número de anos-vida; e equalizar a oportunidade de diferentes indivíduos de passar pelos ciclos vitais. Nos modelos de Biddison e colaboradores ${ }^{19}$ e White e colaboradores ${ }^{20,21}$, esse último objetivo é defendido por meio da alocação 
de mais pontos (quanto maior o escore, menores as probabilidades de sobrevida) com o aumento da faixa etária do paciente. Esse critério é utilizado como parte do modelo principal de White e colaboradores na versão de $2009^{20}$ e como critério de desempate no modelo de Biddison e colaboradores ${ }^{19} \mathrm{e}$ White e colaboradores na versão de $2020^{21}$.

No entanto, após consulta a especialistas em bioética, profissionais da saúde e advogados, nova recomendação para alocar recursos escassos foi publicada ${ }^{6}$, considerando que o critério etário da primeira versão do documento violava o ordenamento jurídico brasileiro e a dignidade do paciente. No protocolo mais recente, as entidades, reforçadas pela Sociedade Brasileira de Geriatria e Gerontologia e pela Academia Nacional de Cuidados Paliativos, sugerem dois escores de desempate, nesta ordem: 1) pontuação total do sequential organ failure assessment (e não a pontuação associada ao quartil utilizada na pontuação geral, observando-se todos os critérios estabelecidos no protocolo final); e 2) julgamento clínico por parte da equipe de triagem ${ }^{6}$. Assim, o modelo de triagem proposto pela Amib passou a usar critério alternativo ao da idade, que, sem impor vieses discriminatórios, reconhece que a gravidade das disfunções orgânicas, a presença de comorbidades e a redução da reserva fisiológica do paciente estão associadas a piores desfechos, como mortalidade hospitalar e mortalidade em longo prazo ${ }^{6}$.

Percebe-se que a idade é critério difundido nos modelos de alocação de recursos. No Brasil, a preocupação com tal critério se amplia devido à diversidade de protocolos, uma vez que não foi estabelecido padrão, e as instituições têm feito suas escolhas individualmente. Diante disso, entende-se que o principal desafio do Estado, dada a dicotomia entre direitos individuais e coletivos, é aperfeiçoar os sistemas de saúde e de justiça. Assim, é preciso planejar estratégias que respeitem a dignidade de cada indivíduo e promovam parâmetros justos e éticos.

\section{O direito ao exercício da autonomia do idoso}

Ao instituir a dignidade da pessoa humana como norteadora de toda ordem jurídica, a Constituição Federal de $1988^{8}$ reconheceu a pluralidade e, com isso, passou a proteger a personalidade e a liberdade para seu desenvolvimento ${ }^{22}$. No entanto, conforme ensina Teixeira, é impossível construir conceito apriorístico e universal de dignidade, pois, num mundo plural, todos têm o direito de construir a própria ideia de dignidade e viver de acordo com ela ${ }^{23}$. Assim, cada pessoa constrói seus valores ideais a partir de sua concepção de vida e história, e não se pode definir conceito que comporte toda essa complexidade.

Nesse contexto, o respeito à autonomia é a base da dignidade, que garante igual liberdade para os indivíduos se projetarem na sociedade. Contudo, também o termo "autonomia" não tem definição unívoca, o que demanda aprofundados estudos e desperta variados debates. Pode-se dizer, entretanto, que as mais influentes teorias se assentam em dois importantes substratos: a liberdade e a qualidade do agente ${ }^{24}$.

Beauchamp e Childress ${ }^{24}$ empregam o termo para examinar a tomada de decisão no cuidado de saúde, propondo que autonomia pressupõe autogoverno. Contudo, é preciso avaliar não a capacidade da pessoa em ser autônoma, e sim se determinado ato foi autônomo. Com isso, o agente deve proceder de maneira intencional, independente e com entendimento, o que pressupõe agir com racionalidade. Esses critérios, no entanto, não são absolutos, haja vista que todo cidadão pode sofrer influências externas, seja por questões afetivas ou morais. Além disso, a capacidade de decisão só costuma ser contestada quando a ação se opõe a valores dominantes. Por isso, dada a complexidade do tema, defende-se que é preciso garantir grau considerável de entendimento e de liberdade, considerando a autonomia em casos concretos ${ }^{24}$.

Nessa perspectiva, Teixeira ${ }^{22}$ entende que a autonomia manifesta a subjetividade, permitindo que o indivíduo elabore as leis que guiarão sua própria vida, desde que estas não divirjam das normas externas ditadas pelo Estado. Portanto, o conceito se refere ao reconhecimento da livre decisão individual, racional e não coagida, sobre seus próprios interesses sempre que não afete terceiros ${ }^{25}$, uma vez que a multiplicidade de valores de determinada sociedade responsabiliza os sujeitos pelas escolhas que fazem. Em consonância, o artigo 50 da DUBDH ${ }^{15}$ afirma que a autonomia pessoal sobre decisões deve ser respeitada desde que se assuma a respectiva responsabilidade e se respeite a autonomia dos outros.

O filósofo e jurista Ronald Dworkin ${ }^{26}$ enfatiza que todas as pessoas têm o direito de tomar decisões importantes para definir sua vida por si próprias. Refletindo sobre o tema, o autor relata algo óbvio, mas que muitas vezes é desconsiderado: nem todos os indivíduos são competentes para exercer as mesmas atividades, mas todos podem mudar de ideia, seja por nova preferência ou para 
corrigir um erro. Isso é autonomia: o direito de decidir, aprender e se responsabilizar pelas próprias ações. Nas palavras de Dworkin, a autonomia exige que permitamos que uma pessoa detenha o controle de sua própria vida, mesmo quando comportar-se de um modo que, para ela própria, não estaria de modo algum de acordo com seus interesses. $O$ valor da autonomia deriva da capacidade que protege: a capacidade de alguém expressar seu caráter valores, compromissos, convicções e interesses críticos e experienciais - na vida que leva ${ }^{27}$.

No entanto, os avanços da ciência e da biotecnologia têm proporcionado aos humanos formas de lidar com as fragilidades do corpo e até ludibriá-las. Na sociedade medicalizada, o prolongamento da vida é visto como objetivo perpétuo, ainda que em cenário pandêmico tal visão seja contradita pelo estabelecimento de um limite à vida com base no critério etário.

Fato é que não se considera a individualidade dos idosos e não se respeita sua autonomia. A falta de concepção de morte digna pressupõe a hierarquização de vidas: quanto mais velha, mais dispensável é a pessoa. Esse preconceito e discriminação contra idosos é definido como "etarismo" e pode ser compreendido a partir da própria estrutura da sociedade brasileira ${ }^{28}$. Assim, a divisão da vida em fases cronológicas - infância, adolescência, idade adulta e velhice - estabelece estereótipos justificados econômica, cultural e socialmente.

O indivíduo é visto pela sua utilidade e suposta contribuição à sociedade. Essa perspectiva, ao classificar a pessoa como "produtiva" ou "não produtiva", acaba por negar sua dignidade e impedir o exercício pleno da autonomia ${ }^{28}$. Deve-se entender que a vulnerabilidade é natural ao envelhecimento, mas não a incapacidade ${ }^{28}$, e que o avanço da idade é sentido de diferentes modos, sendo preciso estabelecer meios para desenvolver habilidades que tornem os idosos ativamente saudáveis. Ademais, é contrassenso beneficiar os mais jovens em detrimento dos mais velhos para que se possa garantir aos primeiros o direito de envelhecer.

O Estatuto do Idoso ${ }^{9}$, por meio de seu artigo 3 , obriga a família, a comunidade, a sociedade e o poder público a proteger integralmente a pessoa idosa. Desse modo, como determina o artigo 80 do mesmo diploma, o envelhecimento é direito personalíssimo e deve ser protegido estabelecendo-se prioridades no cuidado. Em vista disso, ainda que muitas das habilidades motoras diminuam com a idade, dificultando o exercício de certos atos do dia a dia, é preciso vislumbrar o envelhecimento digno e investir nele, valorizando os ideais e a história de vida dos indivíduos. Assim, há de se cumprir o disposto no artigo 10 do Estatuto, que obriga o Estado e a sociedade a assegurar à pessoa idosa a liberdade, o respeito e a dignidade ${ }^{9}$.

Tais orientações têm como base o artigo 3응 da Constituição, que estipula como objetivos fundamentais da República construir uma sociedade livre, justa e solidária; (...) garantir o desenvolvimento nacional; (...) erradicar a pobreza e a marginalização e reduzir as desigualdades sociais e regionais; (...) promover o bem de todos, sem preconceitos de origem, raça, sexo, cor, idade e quaisquer outras formas de discriminação ${ }^{8}$. Como o Estatuto do Idoso ${ }^{9}$, o artigo 230 da Constituição ainda impõe à família, à sociedade e ao Estado o dever de amparar as pessoas idosas, assegurando sua participação na comunidade, defendendo sua dignidade e bem-estar $e$ garantindo-Ihes o direito à vida ${ }^{8}$.

É com base nos direitos e princípios que regem o ordenamento brasileiro que se estabelece o dever de cuidar da pessoa idosa e garantir sua autonomia. Portanto, em tempos de escassez de recursos e falta de infraestrutura, ainda que seja desafiador proteger a pessoa humana, em especial idosos, é crucial promover tutela eficaz. Além disso, é preciso exigir da sociedade e do Estado olhar mais humano e atento às vulnerabilidades que emergem nesse contexto.

\section{Bioética como garantia do respeito à pessoa idosa}

A bioética, ou ética aplicada à vida, é ramo recente, surgido nos Estados Unidos nos anos $1970^{29}$. A palavra foi primeiramente empregada pelo oncologista Van Rensselaer Potter ${ }^{29}$, que, segundo Reich, a definiu como o estudo sistemático da conduta humana no âmbito das ciências da vida e da saúde, enquanto essa conduta é examinada à luz de valores e princípios morais ${ }^{30}$. 0 autor propôs novo campo do conhecimento que ajudasse as pessoas a pensar nas possíveis implicações, positivas ou negativas, dos avanços da ciência sobre a vida humana ou, de maneira mais ampla, de todos os seres vivos. Ele sugeriu que se ligassem duas culturas, a científica e a humanística, guiado pela ideia de que nem tudo que é cientificamente possível é também eticamente aceitável ${ }^{29}$.

Potter concebeu a bioética como interdisciplinar ao afirmar que a ciência é conhecimento, mas não é sabedoria. Sabedoria é o conhecimento 
de como usar a ciência e de como equilibrá-la com outros conhecimentos ${ }^{31}$. A bioética, portanto, é estudo exercido por profissionais de diferentes áreas, que com base em seus pontos de vista e a partir de metodologias, linguagens e histórias próprias debatem visando chegar a consensos. A tomada de decisões dentro desse campo busca solucionar conflitos de valores em um mundo marcado pela intervenção biomédica ${ }^{32}$.

O modelo de análise mais utilizado na bioética latino-americana é o "principalista", introduzido por Beauchamp e Childress ${ }^{24}$ nos anos 1980 e consolidado sobre três princípios: beneficência (não maleficência), autonomia e justiça. Segundo Drummond, essa chamada tríade bioética (...) repousa no médico (pela beneficência [e não maleficência]), no doente (pela autonomia) e na sociedade (pela justiça) ${ }^{33}$. Quanto ao tema que aqui interessa, os referidos princípios proporcionam aos profissionais de saúde forma de dialogar com o idoso.

O princípio da beneficência coloca a promoção do bem-estar do idoso como dever de profissionais e familiares, contemplando não apenas aspectos biológicos, mas também psíquicos e espirituais do paciente, com vistas a melhorar sua qualidade de vida. Já a não maleficência estabelece que qualquer intervenção profissional deve evitar ou minimizar riscos e danos, o que implica não fazer o mal em qualquer hipótese. Ainda que compreendida por Beauchamp e Childress ${ }^{24}$ como desdobramento da beneficência, a não maleficência é comumente considerada princípio bioético autônomo e conceito fundamental da tradição hipocrática, que preconiza o hábito de ajudar alguém ou ao menos não causar danos.

O princípio da justiça diz respeito à distribuição coerente e adequada de deveres e benefícios sociais, salientando a equidade, segundo a qual situações idênticas devem ser tratadas igualmente, e as divergentes, de forma diferente ${ }^{34}$. É preciso, portanto, que profissionais de saúde reconheçam as diferenças de cada paciente e adequem os cuidados a suas necessidades, dando mais atenção aos que mais necessitam dela. Segundo Kottow, todo indivíduo está igualmente exposto, e por isso deve haver acesso indiscriminado e equânime a proteção que outorgue direitos fundamentais, por esta razão denominados universais ${ }^{35}$. Com efeito, os direitos humanos visam reduzir riscos oriundos da vida em sociedade, baseando-se na busca da justiça como direito moral e legal de todo cidadão, bem como no exercício da proteção.

$\mathrm{Na}$ falta de recursos, decisões excludentes ameaçam os mais vulneráveis. Assim, não há como considerar ética qualquer medida que se baseie em caráter universal sem considerar a equidade. A proteção deve se inspirar na justiça, que é universal, mas ao mesmo tempo aplicada às necessidades específicas dos vulnerados ${ }^{36}$.

Como visto, a autonomia se refere à liberdade de ação. Pessoas autônomas são capazes de deliberar e agir de acordo com seus próprios anseios, desde que isso não resulte em danos aos demais (o que exige maturidade e consciência ao fazer escolhas) ${ }^{37}$. O respeito à autonomia na velhice, discutido constantemente pela bioética, envolve não só as decisões de cada paciente quanto aos cuidados, mas também a inevitável influência de familiares e fatores sociais nos processos terapêuticos. Respeitar a autonomia do idoso é tarefa complexa que exige que se ajustem expectativas, que se compreenda a posição do paciente em relação à doença e que se identifiquem as limitações da enfermidade a fim de se adaptar a elas.

No entanto, em situação de emergência e gravidade extrema como a atual, respeitar a autonomia pode criar dilemas entre interesse coletivo e individual. O Estado deve respeitar o direito à saúde e ao mesmo tempo manter equilíbrio entre pretensão e disponibilidade de recursos, sob pena de privilegiar o indivíduo em detrimento da coletividade. Nesse cenário de escassez de recursos, verifica-se a necessidade de determinar ações e serviços de saúde que serão privilegiados, sem deixar de observar os princípios constitucionais do mínimo existencial e da reserva do possível.

É despropositado retirar escassos recursos do Estado e direcioná-los a poucos indivíduos em detrimento da coletividade, uma vez que a saúde é direito constitucional de todo cidadão, diretamente ligado à dignidade da pessoa humana e aos direitos sociais. Por outro lado, é extremamente relevante compreender cada caso concreto, considerando os valores e a biografia do sujeito, fatores que podem auxiliar de modo direto nas difíceis tomadas de decisão da equipe de saúde.

\section{Cuidados paliativos em idosos expostos à covid-19}

A OMS define cuidados paliativos como abordagem para melhorar a qualidade de vida de pacientes e familiares que enfrentam doenças terminais, prevenindo e aliviando o sofrimento por meio de identificação precoce, avaliação $e$ tratamento da dor e de outros problemas físicos, 
psicossociais e espirituais ${ }^{38}$. Esse tipo de assistência afirma a vida e considera a morte processo normal, sem pretender adiá-la, tampouco apressá-la. Aspectos psicológicos e espirituais são integrados de modo a permitir que o paciente viva o mais ativamente possível até a morte, assim como ajudar familiares a lidar com a doença e o luto. Os cuidados paliativos podem ser aplicados durante todo o curso da enfermidade, em conjunto com outras terapias que visam prolongar a vida. Assim, a prática se vale de abordagem interdisciplinar ${ }^{10}$.

Em consonância com a $\mathrm{OMS}^{10}$, a Academia Nacional de Cuidados Paliativos define que essa abordagem é voltada para o controle de sintomas, conforto e qualidade de vida. [O cuidado paliativo] Deve ser oferecido em conjunto com o tratamento padrão de qualquer doença que ameace a continuidade da vida, não devendo jamais ser associado com a omissão ou exclusão (abandono terapêutico), mesmo durante uma pandemia ${ }^{39}$. Assim, esse tipo de assistência deve estar presente sempre que a situação é grave, e não somente quando não é mais possível aplicar cuidados curativos, haja vista que a atenção se torna mais efetiva quando ambas as abordagens são empregadas de forma simultânea, independentemente da idade do paciente ${ }^{40}$.

A atual pandemia compromete a continuidade da vida e provoca sofrimentos de ordem física, emocional, espiritual, social e psicológica não somente no indivíduo infectado pelo vírus e em seus familiares, mas também nas equipes de saúde, que devem tomar decisões urgentes sem evidências científicas suficientes. Tudo isso corrobora a necessidade de que se instituam cuidados paliativos, pois essa abordagem, de baixa tecnologia mas baseada no afeto ${ }^{41}$, pode melhorar a qualidade da assistência, reduzir custos e promover tratamentos mais humanizados e éticos ${ }^{40}$. $O$ importante é que tais cuidados sejam aplicados de forma adequada, e não simplesmente para se eximir de responsabilidades.

Garantir conforto ao paciente é uma das principais finalidades dos cuidados paliativos. Integrar aspectos físicos, psicológicos e espirituais contribui para esse objetivo ao permitir que o doente trabaIhe também a aceitação da morte ${ }^{41}$. A dor é complexa e dinâmica interação de sensações, cognições, condutas e emoções, e é necessário compreender e tratar outros sintomas além dos físicos, que concorrem para agravar o sofrimento ${ }^{42}$. Compreender a finitude como etapa natural e inevitável é crucial para melhorar a experiência no fim de vida, e essa necessidade mostra-se intensa no caso de idosos que enfrentam a covid-19.
Assim, a proposta de restringir o acesso à saúde dos mais idosos, além de discriminatória, pode ser considerada sentença de morte, na medida em que nega cuidados essenciais a esses indivíduos ${ }^{28}$. Nesse cenário, a proposta de integrar cuidados paliativos não deve ser encarada como resposta à escassez de recursos ou mera alternativa à inegável discriminação. A defesa dessa abordagem tem como intuito assegurar aos indivíduos expostos ao vírus - e principalmente aos mais vulneráveis o acesso a tratamento adequado, capaz de proporcionar melhor qualidade de vida, pois, como visto, a dor não resulta somente de fatores físicos ${ }^{42}$.

Prata ${ }^{41}$ ensina que qualidade de vida é noção subjetiva que influencia a escolha terapêutica, pois, ainda que haja protocolos, não há um tratamento único que seja adequado a todos os casos. Assim, os cuidados paliativos exigem assistência personalizada, que respeite a vida, os valores e a personalidade de cada indivíduo ${ }^{41}$. O respeito à autonomia é a chave principal, e mesmo em momentos críticos como o da pandemia, em que o interesse social deve preponderar, é preciso que a equipe se paute em comunicação realmente adaptada e dinamizada, dando segurança ao paciente sobre a conduta a ser tomada. A abordagem humanista compreende que é o próprio sujeito o motivo de todos os esforços e cuidados, tratando o paciente como pessoa, dentro de seu sistema de valores ${ }^{43}$, assegurando-Ihe conforto e tratamento dos sintomas.

\section{Considerações finais}

Visto que não há precedentes históricos recentes para a dinâmica de atendimentos em pandemia, os profissionais que lidam com a situação concreta se veem impelidos a escolher quem deve ser atendido. Nesse cenário, a bioética tem importante papel, pois pode estabelecer práticas e protocolos para a tomada de decisões por meio dos princípios da beneficência, da não maleficência, da autonomia e da justiça. De acordo com esses princípios, mesmo em cenário de escassos recursos em saúde, determinar um limite para a vida tendo como base o critério etário é ato discriminatório.

Reinterpretar a posição do idoso na pandemia não é fácil, visto que o senso comum o vê como indivíduo inválido, próximo da morte. É crucial, porém, compreendê-lo como sujeito de valores, que tem seus direitos amparados pelo ordenamento jurídico. Nesse contexto, os cuidados paliativos deveriam ser ofertados não como solução para a escassez de 
recursos, mas como necessidade, uma vez que esse tipo de assistência visa garantir a dignidade, a autonomia e o respeito aos valores da pessoa. Quando as tecnologias médicas não são suficientes para assegurar a cura, é imprescindível que se lide com a morte. Portanto, garantir melhores experiências nesse momento, em consonância com aquilo que o paciente considera "qualidade de vida", é primordial para respeitar a autonomia em situações nas quais o interesse social é preponderante.

\section{Referências}

1. Folha informativa covid-19: escritório da Opas e da OMS no Brasil. Organização Pan-Americana da Saúde [Internet]. 2020 [acesso 29 abr 2020]. Disponível: https://bit.ly/3lvKEB|

2. Sociedade Brasileira de Pediatria. Novo coronavírus (covid-19) [Internet]. Rio de Janeiro: SBP; 2020 [acesso 29 abr 2020]. Disponível: https://bit.ly/3ljvLSO

3. Brasil. Ministério da Saúde. Protocolo de manejo clínico para o novo coronavírus (2019-nCoV) [Internet]. Brasília: Ministério da Saúde; 2020 [acesso 29 abr 2020]. Disponível: https://bit.ly/2GxfWJA

4. Vergano M, Bertolini G, Giannini A, Gristina G, Livigni S, Mistraletti G, Petrini F. Raccomandazioni di etica clinica per l'ammissione a trattamenti intensivi e per la loro sospensione: in condizioni eccezionali di squilibrio tra necessità e risorse disponibili [Internet]. Roma: Società Italiana di Anestesia Analgesia Rianimazione e Terapia Intensiva; 2020 [acesso 18 abr 2020]. Disponível: https://bit.ly/2lbU8DJ

5. Kretzer L, Berbigier E, Lisboa R, Grumann AC, Andrade J. Protocolo Amib de alocação de recursos em esgotamento durante a pandemia por covid-19 [Internet]. São Paulo: Amib; 2020 [acesso 10 maio 2020]. Disponível: https://bit.ly/34Anbll

6. Kretzer L, Berbigier E, Lisboa R, Grumann AC, Andrade J. Recomendações da Amib (Associação de Medicina Intensiva Brasileira), Abramede (Associação Brasileira de Medicina de Emergência), SBGG (Sociedade Brasileira de Geriatria e Gerontologia) e ANCP (Academia Nacional de Cuidados Paliativos) de alocação de recursos em esgotamento durante a pandemia por covid-19 [Internet]. São Paulo: Amib; 2020 [acesso 10 maio 2020]. Disponível: https://bit.ly/2SAwEtO

7. Ognibene $\mathrm{F}$. Coronavirus: ricoveri in terapia intensiva secondo speranza di vita e limiti di età. Avvenire [Internet]. 7 mar 2020 [acesso 29 abr 2020]. Disponível: https://bit.ly/3iJCqUH

8. Brasil. Constituição da República Federativa do Brasil [Internet]. Brasília: Senado Federal; 2016 [acesso 29 abr 2020]. Disponível: https://bit.ly/2YjzyT0

9. Brasil. Lei no 10.741, de 10 de outubro de 2003. Dispõe sobre o Estatuto do Idoso e dá outras providências. Diário Oficial da União [Internet]. Brasília, 3 out 2003 [acesso 29 abr 2020]. Disponível: https://bit.ly/3lucBKa

10. World Health Organization. Palliative care [Internet]. 2020 [acesso 15 maio 2020]. Disponível: https://bit.ly/3iDOqa1

11. World Health Organization. Integrating palliative care and symptom relief into the response to humanitarian emergencies and crises: a WHO guide [Internet]. Geneva: WHO; 2018 [acesso 25 ago 2020]. Disponível: https://bit.ly/30LHdPc

12. Leitão J Jr, Mousinho PRC. O coronavírus, o direito penal e a "escolha de Sofia": medicina de catástrofe. Jusbrasil [Internet]. 2020 [acesso 29 abr 2020]. Disponível: https://bit.ly/3lqiveZ

13. Escolhas de Sofia [podcast]. Finitude [Internet]. 2020 [acesso 29 abr 2020]. Disponível: https://bit.ly/3nvcGie

14. Sociedade Brasileira de Bioética. Recomendação SBB no 1/2020: aspectos éticos no enfrentamento da covid-19, em defesa dos mais vulneráveis e do acesso igualitário aos leitos de UTI [Internet]. Brasília: SBB; 2020 [acesso 18 maio 2020]. Disponível: https://bit.ly/3lw3AQJ

15. Organização das Nações Unidas para a Educação, a Ciência e a Cultura. Declaração universal sobre bioética e direitos humanos [Internet]. Lisboa: Unesco; 2006 [acesso 15 abr 2020]. Disponível: https://bit.ly/2ONefYM

16. Organização das Nações Unidas. Pacto internacional dos direitos econômicos, sociais e culturais [Internet]. Washington: Organization of American States; 2010 [acesso 18 maio 2020]. Disponível: https://bit.ly/2SEDGOI

17. Organização das Nações Unidas. Declaração universal dos direitos humanos [Internet]. Brasília: Unesco; 1998 [acesso 18 maio 2020]. Disponível: https://bit.ly/2GDR1E3

18. Rodríguez Yago MA. Comunicado del Plan Nacional de RCP en relación a la situación derivada por la epidemia covid-19 [Internet]. Madrid: Semicyuc; 2020 [acesso 29 abr 2020]. Disponível: https://bit.ly/2GOLjPz

19. Biddison ELD, Faden R, Gwon HS, Mareiniss DP, Regenberg AC, Schoch-Spana $M$ et al. Too many patients... A framework to guide statewide allocation of scarce mechanical ventilation during disasters. Chest [Internet]. 2019 [acesso 10 maio 2020];155(4):848-54. DOI: 10.1016/j.chest.2018.09.025

20. White DB, Katz MH, Luce JM. Who should receive life support during a public health emergency? Using ethical principles to improve allocation decisions. Ann Intern Med [Internet]. 2009 [acesso 1o maio 2020];150(2):132-8. Disponível: https://bit.ly/36LcOEv 
21. White DB, Katz M, Luce J, Lo B, Biddison LD, Toner E, Halpern S. Allocation of scarce critical care resources during a public health emergency [Internet]. Pittsburgh: University of Pittsburgh; 15 abr 2020 [acesso 10 maio 2020]. Disponível: https://bit.ly/2FiMEOE

22. Teixeira ACB. Autonomia existencial. Rev Bras Direito Civ [Internet]. 2018 [acesso 1 o maio 2020];16:75-104. Disponível: https://bit.ly/3jlqKmv

23. Teixeira ACB. Op. cit. p. 78.

24. Beauchamp TL, Childress JF. Princípios de ética biomédica. São Paulo: Loyola; 2002.

25. Teixeira ACB. Op. cit. p. 95.

26. Dworkin R. Domínio da vida: aborto, eutanásia e liberdades individuais. São Paulo: Martins Fontes; 2003.

27. Dworkin R. Op. cit. p. 318-9.

28. Dadalto L, Mascarenas IL, Matos AKH. Salvem também os idosos: etarismo e a alocação de recursos na realidade brasileira de combate ao covid. Civilística.com [Internet]. 2020 [acesso 14 set 2020];9(2):1-19. Ahead of print. Disponível: https://bit.ly/3nxL7ol

29. Potter VR. Bioethics: bridge to the future. Englewood Cliffs: Prentice Hall; 1971.

30. Reich WT. Encyclopedia of bioethics. New York: Free Press-Macmillan; 1978. p. 19. Tradução livre.

31. Potter VR. Op. cit. p. 49. Tradução livre.

32. Llano Escobar A. Funciones del bioeticista. Selecc Bioét [Internet]. 2002 [acesso 8 out 2020];2:218. Disponível: https://bit.ly/3nvcTIF

33. Drummond JP. Bioética, dor e sofrimento. Ciênc Cult [Internet]. 2011 [acesso 26 out 2020];63(2):32-7. p. 32. DOI: 10.21800/S0009-67252011000200011

34. Clotet J. Bioética: uma aproximação. Porto Alegre: EdiPUCRS; 2003.

35. Kottow M. Ética de protección: una propuesta de protección bioética. Bogotá: Universidad Nacional de Colombia; 2007. p. 246. Tradução livre.

36. Schramm FR. Bioética sem universalidade? Justificação de uma bioética latino-americana $e$ caribenha de proteção. In: Garrafa V, Kottow M, Saada A, organizadores. Bases conceituais da bioética: enfoque latino-americano. São Paulo: Gaia; 2006. p. 143-57.

37. Nunes L. Ética em cuidados paliativos: limites ao investimento curativo. Rev. Bioética [Internet]. 2008 [acesso 29 abr 2020];16(1):41-50. Disponível: https://bit.ly/3ljRJoK

38. World Health Organization. Op. cit. 2020. Tradução livre.

39. Academia Nacional de Cuidados Paliativos. Covid-19 [Internet]. 2020 [acesso 26 ago 2020]. Disponível: https://bit.ly/3jJM7DU

40. Academia Nacional de Cuidados Paliativos. Reconhecimento da medicina paliativa como especialidade médica [Internet]. 19 jun 2017 [acesso 29 abr 2020]. Disponível: https://bit.ly/3di4Xzt

41. Prata HM. Cuidados paliativos e direitos do paciente terminal. Barueri: Manole; 2017.

42. Sapeta P. Dor total vs. sofrimento: a interface com os cuidados paliativos. Dor [Internet]. 2007 [acesso 8 out 2020];15:16-21. Disponível: https://bit.ly/3lrAWQx

43. Prata HM. Op. cit. p. 207

Participação das autoras

Ana Sarah Vilela de Oliveira e Juliana Campos Machado contribuíram igualmente para a elaboração do artigo. Luciana Dadalto orientou o projeto e executou a revisão crítica.

\section{Correspondência}

Ana Sarah Vilela de Oliveira - Rua Necésia Nunes dos Santos, 61, Pôr do Sol CEP 37220-000. Bom Sucesso/MG, Brasil.

Ana Sarah Vilela de Oliveira - Graduanda - ana.oliveira1@estudante.ufla.br

(iD) 0000-0003-2960-7060

Juliana Campos Machado - Graduanda - julianacm_23@yahoo.com.br

(iD) 0000-0002-9651-1651

Luciana Dadalto - Doutora - luciana@lucianadadalto.com.br

(iD) 0000-0001-5449-6855 